\title{
Suppression of drinking by parenteral administration of carbachol ${ }^{1}$
}

KHALIL A. KHAVARI

UNIVERSITY OF WISCONSIN, MILWAUKEE

Application of the cholinomimetic drug, carbachol, to specific CNS structures is reported by many investigators to enhance water intake in rats. In contrast, the present experiment shows that parenteral administration of carbachol suppresses water intake.

Carbachol is considered to have pharmacological properties similar to acetylcholine (Volle, 1965). In addition to being the most powerful of all the choline esters, carbachol is hydrolized very slowly by acetylcholinesterase. There is also evidence that the drug possesses anticholinesterase properties, probably as a result of carbonic ester grouping in the molecule (Ricker \& Wescoe, 1946). However, the additive effects of carbachol and anticholinesterase administered concomitantly indicates that the cholinergic action of carbachol is a direct one and not effective via its anticholinesterase property (Goodman \& Gilman, 1960).

It has been demonstrated that application of carbachol to a number of CNS structures significantly enhances water intake of rats (Grossman, 1960; Miller, 1965; Levitt \& Fisher, 1966). This enhancement is generally attributed to cholinergic stimulation effects on certain CNS structures.

In the present work, attempts were made to evaluate the effects of peripheral cholinergic stimulation on drinking. Carbachol is a quaternary compound and passes the blood-brain barrier with extreme difficulty (Schanker, 1962). Therefore, parenteral administration of the drug is expected to affect primarily the peripheral structures and processes. Method

The Ss were 40 naive, male albino rats of the Sprague-Dawley strain, between 90-120 days old at the beginning of the experiment. The apparatus consisted of wire mesh cages of $8 \times 8 \times 11$ in. Each cage was fitted with a graduated tube with a drinking pipe which served as the source of water. All Ss were maintained on a $23-h$ water deprivation schedule. Dry laboratory rat food was available at all times except during the 1-h test session. In each daily test session the $S$ had access to $9 \%$ sugar water, for $1 \mathrm{~h}$, in the apparatus. After preliminary adaptation to the apparatus and stabilization of intake, the Ss were randomly divided into four equal groups and each group was assigned to a particular dose of carbachol. All drug and saline injections were administered intraperitoneally (IP) Immediately prior to the 1-h test sessions. Distilled water was used as the vehicle for all drug injections. The volume injected, for both saline and drug, was $1.0 \mathrm{ml} / \mathrm{kg}$ body weight. Each rat received the following sequential treatments: The first day constituted the No Injection session in which the $S$ was placed in the apparatus for $1 \mathrm{~h}$ and its total intake was recorded at the end of the session; the second day was the Pre-Drug session in which the rat received an IP injection of physiological saline prior to the test; the third day was the Drug day in which the rat was given its assigned dose of carbachol; and finally, in the fourth day, Post-Drug, the rat was injected with saline before the test.

Table 1 presents: doses of carbachol employed; mean values of intake, in $\mathrm{ml}$, and standard errors for Pre-Drug and Drug session; and statistical significance of the difference, between intakes during the two sessions, as determined by correlated test. Results and Discussion

Application of the cholinomimetic drug, carbachol, to specific CNS structures implicated in the drinking circuit (Levitt \& Fisher, 1966) results in enhancement of water intake. In contrast to its central effects, parenteral carbachol significantly suppressed water intake at all dose levels tested in the present experiment (a check experiment showed that carbachol affects drinking in a similar way with either water or sugar water). Statistical tests, summarized in Table 1, confirm that drinking was suppressed with all three doses of the drug as compared to the amount of intake during Pre-Drug sessions. No data were collected from the group treated with $2.0 \mathrm{ml} /$ $\mathrm{kg}$ of carbachol. Nine of the Ss from this group died within $20 \mathrm{~min}$ after injection, while the tenth rat remained relatively normal and consumed a few milliliters of the solution during the session.

It is significant to note that the same cholinomimetic drug, carbachol, affects drinking in a diametrically opposed fashion depending on the route of application employed. Two conclusions, therefore, can be stated on the basis of the present finding. Flrst, drinking behavior is not under the exclusive control of central mechanisms. Second, the neuroTable 1. Mean intake in ml during PRE-DRUG and DRUG 1-h tests. Standard errors are shown in parentheses.

\begin{tabular}{lcc}
$\begin{array}{l}\text { Doses } \\
(\mathrm{mg} / \mathrm{kg})\end{array}$ & Pre Drug & Drug \\
\hline 0.25 & $21.6(1.06)$ & $15.4(2.10)^{*}$ \\
0.50 & $21.9(1.13)$ & $13.7(1.16)^{*}$ \\
1.00 & $27.0(1.36)$ & $7.2(2.83)^{*}$ \\
\hline
\end{tabular}

* Significantly different from Pre Drug, $p<.05$. 
chemical code underlying the drinking behavior is highly complex and has not been fully delineated and understood.

\section{References}

GOODMAN, L. S., \& GILMAN, A. The pharmacological basis of therapeutics. (2nd ed.) New York: MacMillan, 1960.

GROSSMAN, S. P. Eating and drinking elicited by direct adrenergic and cholinergic stimulation of hypothalamus. Science, 1960, 132,

LEVITT, R. A., \& FISHER, A. E. Anticholinergic blockade of centrally induced thirst. Science, 1966, 154, 520-521.
MILLER, N. E. Chemical coding of behavior in the brain. Science, 1965, RICKER, W. E., JR., \& WESCOE, W. C. The direct action of prostigmine on skeletal muscle; its relationship to the cholinesters. $J$. Pharmacol \& Exp. Therap., 1946, 88, 58-66.

SCHANKER, L. S. Passage of drugs across body membranes. Pharmacol Rev., 1962, 14, 501-530.

VOLLE, R. L. The cholinergic drugs. In J. R. Dipalma (Ed.), Drill's pharmacology in medicine. (3rd ed.) New York: McGraw-Hill, 1965. Note

1. This research was supported by the Graduate School of the University of Wisconsin, Milwaukee and NIH research grant MH-06997. 